\title{
A Comparative Study of Male and Female Hostlers on
}

\section{Spirituality and Quality of Life}

\author{
Deoshree Akhouri ${ }^{1}$, Kehksha²*, S. A. Azmi ${ }^{3}$
}

\section{ABSTRACT}

Spirituality may refer as a subjective feeling and experiences that occur both within and outside of traditional religious systems that influence various domains of life e.g. physical health, mental health, optimism, resilience and quality of life. The aim of the present study is to explore the relation between spirituality and quality of life in male and female hostlers. To accomplish the goal of study, we selected 100 girls and 100 boys post graduate students from Aligarh Muslim University through random sampling method. The entire participants were hostlers whom age ranges from 18-24 years. We applied Daily spiritual experience scale (DSES) and WHOQOLBREF on the participants to collect data. We analyzed data with the help of t-test and Pearson product moment co-efficient of correlation. The results indicate positive relationship between spirituality and quality of life. Result also shows the difference between male and female hostlers on spirituality and quality of life.

Keywords: Spirituality, Quality of Life, Hostlers, Subjective Feeling.

Through the last decade researcher noticed spirituality and considers its influence on health related issues (Ridnour, 2008). Spirituality seems to be related to various facets of mental and physical health while the acceptance of spirituality as a firm component of good mental and physical health has become more standardized (Moberg \& Bruseck, 1978). Spirituality is a different and broad phenomenon. Canda (1990) defined spirituality as the "person's search for a sense of meaning and morally fulfilling relationships between oneself, other people, the encompassing universe, and the ontological ground for existence”. Spirituality is not the same as religion because religion includes spiritual assurances and practices that is maintained by society and culture over time. Vaughan et al. (1996) defined spirituality as "a subjective experience that exists both within and outside of traditional religious systems" and by Sussman et al. (1997), it is a "subjectively experiencing a life force". Spiritual experience can also be defined as

\footnotetext{
${ }^{1}$ Assistant Professor, Department of Psychiatry, J.N. Medical College, A.M.U

${ }^{2}$ Department of Psychiatry, J.N. Medical college, A.M.U. Aligarh

${ }^{3}$ Professor, Department of Psychiatry, JawaharLal Nehru Medical College, Aligarh Muslim University, Aligarh

*Responding Author (c) 2016 I D Akhouri, Kehksha, A Azmi; licensee IJIP. This is an Open Access Research distributed under the terms of the Creative Commons Attribution License (http://creativecommons.org/licenses/by/2.0), which permits unrestricted use, distribution, and reproduction in any Medium, provided the original work is properly cited.
} 


\section{A Comparative Study of Male and Female Hostlers on Spirituality and Quality of Life}

"experiences that may or may not be part of daily life, and reflect the perception of interacting and being involved with the sacred” (Larson et al., 1998). Larson et al. (1998) identified the following domains of spirituality

(a) Religious/spirituality preference or affiliation

(b) Religious/spiritual history

(c) Religious/spiritual participation

(d) Religious/spiritual private practices

(e) Religious/spiritual support

(f) Religious/spiritual coping

(g) Religious/spiritual beliefs and values

(h) Religious/spiritual commitment

(i) Religious/spiritual motivation for regulating and reconciling relationships

(j) Religious/spiritual experiences

WHO defines quality of life as “individuals' perception of their position in life in the context of the culture and value systems in which they live and in relation to their goals, expectations, standards and concerns. It is a broad-ranging concept affected in a complex way by the persons' physical health, psychological state, level of independence, social relationships and their relationships to salient features of their environment” (Skevington et al., 2004). Mytko and Knight (1999) defined quality of life as a multidimensional construct that includes the patient's perspective of their overall quality of life and their assessment of specific components of quality of life i.e., physical, psychological and social well-being. Quality of life involves a onedimension that is affected by numerous factors. In addition, quality of life is conceptualized as a subjective phenomenon that includes other subjective concepts such as life satisfaction and wellbeing. Spirituality can be understood as a phenomenon that is predictor of quality of life, but it remains distinctive from other physical, social and psychological well-being. Similarly, physical, social and psychological well-being is also related to quality of life. Mirmoeini and Afsharinia (2015) determined the relationships between spirituality and resiliency with quality of life of students. Results showed that $86 \%$ of the variance predict the quality of life and also it showed that the meaning full relation between spirituality and resiliency with the quality of life. Similarly, in another study done by Bellamy and colleagues (2007) on 1,835 people with mental illness involved in clubhouse and consumer drop-in centers in the United States, they reported spirituality was related to overall quality of life. Krageloh, Henning, Billington, Hawken (2015) investigated the effects of spirituality, religiousness, and personal beliefs on the quality of life (QOL) of medical students affiliated with a religious faith and those without affiliation. For religious students, a larger range of characteristics of existential beliefs were positively related to quality of life. For all students, hope and optimism and meaning of life predicted higher scores on psychological wellbeing. For religious and nonreligious medical students, reduced meaning in life and hope were the strongest indicators of psychological distress. 
Statement of the problem-On the previous research and theoretical assumption, we tried to examine the effect of spirituality on quality of life and compare male and female hostlers on spirituality and quality of life.

\section{OBJECTIVES OF THE STUDY}

- To examine the effect of spirituality on quality of life on male and female hostlers

- To establish relationship between spirituality and quality of life

- To compare male and female hostlers on spirituality and quality of life

\section{Hypotheses}

- There is no significant difference between male and female hostlers on spirituality

- There is no significant difference between male and female hostlers on quality of life

- There is no significant relationship between spirituality and quality of life

\section{METHODOLOGY}

\section{Sample-}

The purpose of the present study is to examine the effect of spirituality on quality of life between male and female hostlers and compare male and female hostlers on spirituality and quality of life. Therefore sample of the present study was those students who were hostlers and perusing post-graduation. For conducting this study, we selected 100 boys and 100 girls hostlers from the hostels of Aligarh Muslim University through random sampling technique.

\section{Tools of the study}

Daily Spiritual Experience Scale (DSES)-We applied Daily spiritual experience scale to assess the degree of spirituality among hostlers. L.G. Underwood and J.A. Teresi developed this scale in 2002 that comprised of 16 items. The internal consistency reliability of DSES is estimated with Cronbach's alpha .94 that is very high.

WHOQOL-BREF-We used WHOQOL-BREF to assess quality of life of hostlers. World Health Organization developed this scale in 2004. This scale consists of 26 items that assess four domains of health that are physical, psychological, social and environmental. Chronbach alpha for this scale has been found 0.925 .

\section{Procedure-}

For collecting data, we approached all the participants through the hostels' administration. Before starting the procedure, we established good rapport with the participants and took them into confidence and make them sure about the confidentiality of their responses. We took their consent before distribution of all the questionnaires among them. We gave them Instructions as printed on questionnaires. After filling both the questionnaires, we collected all the questionnaires and respondents thanked the respondents for their cooperation. After collecting raw data, we did statistical calculation with the help of SPSS 17.0. 


\section{RESULT}

Analysis of data- To compare male and female hostlers on spirituality and quality of life, we used t-test and to find out relationship between spirituality and quality of life, we used Pearson Product Moment Coefficient of Correlation. Following tables show the result.

Table 1showsMean, S.D. and t-value of male and female hostlers on spirituality

\begin{tabular}{|l|l|l|l|l|l|l|l|}
\hline Group & $\mathbf{N}$ & Mean & S.D. & t-value & d.f. & Sig & Result \\
\hline Female & 100 & 62.51 & 15.55 & $.872^{*}$ & 99 & .000 & Significant \\
\cline { 1 - 4 } & 100 & 60.57 & 13.32 & & & & \\
\hline
\end{tabular}

*Significant at the 0.05 level $\%$ of critical value

Above table indicates mean score of spirituality for male and female. We found mean score for female on spirituality 62.51 and for male hostlers60.57 respectively. It means female are more spiritual than male. T- value of spirituality for female and male hostlers was .872 that is significant at 0.05 level of critical ratio. It indicates that there is significant difference between male and female hostlers on spirituality.

Table 2 shows Mean, S.D. and t-value of male and female hostlers on quality of life

\begin{tabular}{|l|l|l|l|l|l|l|l|}
\hline Group & $\mathbf{N}$ & Mean & S.D. & t-value & d.f. & Sig & Result \\
\cline { 1 - 5 } Female & 100 & 86.79 & 10.99 & $21.519^{*}$ & 99 & .000 & Significant \\
\cline { 1 - 4 } Male & 100 & 82.22 & 11.00 & & & & \\
\hline
\end{tabular}

*Significant at the 0.05 level

We can observe clearly that the mean score of quality of life for female and male are 86.79 and 82.22 respectively. It means female have better quality of life than male hostlers. T- value of quality of life was 21.519 that is significant at 0.05 level of critical ratio. The $t$-value indicates that female and male differ significantly on quality of life.

Table 3 shows Mean, S.D. and r-value between spirituality and quality of life for female hostlers

\begin{tabular}{|l|l|l|l|l|l|l|l|}
\hline Group & $\mathbf{N}$ & Variables & Mean & S.D. & r value & sig & Result \\
\hline Female & \multirow{2}{*}{100} & Quality of life & 86.79 & 10.991 & $.726^{* *}$ & .000 & Significant \\
\cline { 3 - 5 } & & Spirituality & 62.747 & 15.518 & & & \\
\hline
\end{tabular}

** Correlation is significant at the 0.01 level (2-tailed)

Above table presents r- value for spirituality and quality of life for female hostlers. The r- value between spirituality and quality of life for female hostlers was .726 that is significant at 0.01 
level of confidence. On the basis of present table it is evident that there is significantly high positive correlation between spirituality and quality of life.

Table 4 shows Mean, S.D. and r-value between spirituality and quality of life for male hostlers

\begin{tabular}{|l|l|l|l|l|l|l|l|}
\hline Group & $\mathbf{N}$ & Variables & Mean & S.D. & r value & sig & Result \\
\hline \multirow{2}{*}{ Male } & \multirow{2}{*}{100} & Quality of life & 82.22 & 11.00 & $.508^{* *}$ & .000 & Significant \\
\cline { 3 - 5 } & & Spirituality & 60.57 & 13.32 & & & \\
\hline
\end{tabular}

** Correlation is significant at the 0.01 level (2-tailed)

Above table presents $\mathrm{r}$ - value for spirituality and quality of life for male hostlers. We found rvalue between spirituality and quality of life for male hostlers.508 that is significant at 0.01 level of confidence. It demonstrates significantly average positive relationship between spirituality and quality of life.

\section{DISCUSSION}

We conducted present study to compare male and female hostlers on spirituality and quality of life and to assess the impact of spirituality on quality of life. Findings of the present study revealed that-

There was significant difference between male and female hostler's interims of spirituality. Male hostlers scored lowered on spirituality than female hostlers. The cause behind this may be that all the subjects were from Muslim community and there were held spiritual meeting daily in girls' hostel. The present study is supported by Bryant (2007) who found that women are more spiritual than men. Hammermeisteret. al. (2005) also found the same result.

We also found that there was significant difference between male and female on quality of life. Female hostlers showed better quality of life than male hostlers. The cause behind this may be the higher spirituality in female that lead female to possess better quality of life. Besides this, Muslim females showed less responsibility toward their family and tension of their carrier that may be also a significant predictor of quality of life. Study of Mihaela Chraifa and Daniela Dumitrub (2015) supports the present study. They also explored differences between genders in terms of quality of life and well-being among undergraduate students.

It was also found that spirituality is highly and positively related with quality of life for female hostlers. It reveals that high level of spirituality can improve quality of life of female hostlers that can help the female hostlers to overcome the feelings of loneliness, distrust and mental health that is a great issue of newcomers in hostels. This finding is supported byAdel Mirzaei1et.al (2014). They found significantly positive relationship between quality of life and spiritual well-being in their study. 


\section{A Comparative Study of Male and Female Hostlers on Spirituality and Quality of Life}

There was average positive relation between spirituality and quality of life among male hostlers. This relationship is not as stronger in male hostlers as in the female hostlers. Reason behind this may be that male hostlers have less spirituality than female hostlers that result in less quality of life in male hostlers.

There was average positive relation between spirituality and quality of life among male hostlers. This relationship is notstronger in male in comparison to female hostlers. Reason may be that male hostlers are less spiritual than female hostlers. Therefore they have been found to have less quality of life in comparison to female hostlers.

Mirmoeini and Afsharinia (2015) determined the relationships between spirituality and resiliency with Quality of life among students. Their study supports our present study.

\section{CONCLUSION}

On the basis of obtained result, we can conclude that the significant difference existed between female and male hostlers on spirituality and quality of life. They differ with each other on spirituality and quality of life. This study explored that female are more spiritual than male hostlers and female have better quality of life than male hostlers as well as there has been found highly positive relationship between spirituality and quality of life.

\section{LIMITATIONS OF THE STUDY}

We conducted the present study on the Muslim girls and boys in which girl hostlers are exposed to spiritual and religious meetings daily but these meetings are unavailable in the boys' hostels. Results may be changed if study would involve participants of different religions and different institutions. Along with large sample may change the result of the study.

\section{REFERENCE}

Abeles, R., Ellison, C., George, L. K., Idler, E., Krause, N., Levin, J., et al. D. (1999).Multidimensional measurement of religiousness/ spirituality for use in health research. Kalamazoo, MI: Fetzer Institute \& National Institute on Aging Working Group.

Ballemy, C.D., Jarrett, N.C.,Mowbray, O., MacFartane, P., Mowbray, C.T., and Holter, M.C.(2007).Relevance of spirituality for people with mental illness attending consumercentered service. Psychiatry Rehabilitation Journal, 30(40), 287-294.

Beckie, T. M., \& Hayduk, L. A. (1997).Measuring quality of life. Social Indicators Research, 42, 21-37.

Bryant, A. N. (2007). Gender differences in spiritual development during the college years. Sex Roles, 56(11-12), 835-846. doi: 10.1007/s11199-007-9240-2

Burke, K. (2006). Religion, spirituality and health.In Gehlert, S. and Browne, T.A. (Eds), handbook of health social work 282-394. John wiley and son inc.

Canda, E.R. (1990). Afterword: spirituality reexamined. Spiritualty and social work communicator, 1(1), 13-14.

Chraifa, M., Daniela, D., (2015).Gender differences on Wellbeing and Quality of life at young students at psychology, Procedia- Social and Behavioral Sciences 180, 1579 - 1583. 


\section{A Comparative Study of Male and Female Hostlers on Spirituality and Quality of Life}

Corrigan, P., Mcrkle, B., Schell, B., Kidder, K. (2003).Religion and Spirituality in the Lives of People with Serious Mental Illness. Community Mental Health Journal, 39(6), 487-499.

Emblen, J. D. (1992). Religion and spirituality defined according to current use in nursing literature. Journal of Professional Nursing, 8(1), 41-47.

Hammermeister, J., Flint, M., El-Alayli, A., Ridnour, H., \& Peterson, M. (2005). Gender differences in spiritual well-being: Are females more spiritually-well than males? American Journal of Health Studies, 20(2), 80-84.

Krageloh CU, Henning MA, Billington R, Hawken SJ.(2015) The relationship between quality of life and spirituality, religiousness, and personal beliefs of medical students.Academy psychiatry 39(1) 85-9.

Larson, D. B., Sawyers, J. P., \& McCullough, M. E. (1998). Scientific research on spirituality and health: A report based on the Scientific Progress in Spirituality Conferences. New York: John M. Templeton Foundation.

Mirmoeini, F.,Afshariniav, K. (2015).The Relationship between Spirituality and Resiliency with Quality of Life among Students of Islamic Azad University of Sciences and Researches of Kermanshah. International journal of AYER, 3, 68-74 ISSN: 1134-2277.

Mirzaei, A. Banayi, N, Ghasemi, M, Jahansa, N, Mashreghi, Z.A. (2014). the relationship between spiritual well-being with quality of life on martial art athletes, Reef Resources Assessment and Management Technical Paper, 40(1), 771-775.

Moberg, D. O. \&Brusek, P. M. (1978).Spiritual well-being: A neglected subject in quality of life research. Social Indicators Research, 5, 303-323.

Mytko, J. J., Knight, S. J. (1999). Body, mind and spirit: Towards the integration of religiosity and spirituality in cancer quality of life research. Psycho-Oncology, 8, 439-450.

Orley, J., Saxena, S., Herrman, H. (1998). Quality of life and mental illness. British Journal of Psychiatry, 172, 291-293.

Ridnour, Heather Hammermeister, Jon (2008) Spiritual well-being and its influence on athletic coping profiles. Journal of Sport Behavior Publisher. Source Volume: 31 Source Issue:

Skevington S. M., Lotfy, M., O’Connell, K. A. (2004). The World Health Organization's WHOQOL-BREF quality of life assessment: Psychometric properties and results of the international field trial - A report from the WHOQOL group. Quality of Life Research, 13, 299-310.

Sussman, S., Nezami, E., \& Mishra, S. (1997). On operational zing spiritual experience for health promotion research and practice. Alternative Therapies in Clinical Practice, 4, 120125.

Thoresen, C. E. (1999). Spirituality and health: Is there a relationship? Journal of Health Psychology, 4, 291-300.

Thoresen, C.E., Harris, A.H.S., \& Oman, D. (2001). Spirituality, religion and health: Evidence, issues and concerns. In Plante, T.G.., \& Sherman, A.C. (Eds.), Faith and health: Psychological perspectives (15-52).New York: Guilford Press. 
Vaughan, F., Wittine, B., Walsh, R. (1996).Transpersonal psychology and the religious person. In E. D. Shafranske (Ed.), Religion and the clinical practice of psychology (483-510). Washington, DC: American Psychological Association. 